\title{
Building a Collective Sense of Who we are - A Chart for Anthropological Perspectives on Organizational Identity Construction
}

\author{
Bing Ran* \\ School of Public Affairs, Penn State Harrisburg, Middletown, USA
}

*Corresponding author: Bing Ran, School of Public Affairs, Penn State Harrisburg, Middletown, PA 17057, USA

\section{Short Communication}

Anthropology has a long history of studying individual identitymaking and identity construction, but not enough attention has been paid to organizational identity constructions. [1] worried by the anthropological lack of attention to organizations. He said: "Organization is key because it sets up relationships, among people through allocation and control of resources and rewards. It draws on tactical power to monopolize or share out liens and claims, to channel action into certain pathways while interdicting the flow of our action into others. Some things become possible and likely; others are rendered unlikely. At the same time, organization is always at risk. Since power balances always shift and change, its work is never done" [1]. Following Wolf's call on organizational studies, this paper calls for more anthropological studies on how organizations answer the question of "who are we" and "how do we get there" and points out the necessity of a comprehensive framework on organizational identity construction that should examine the contextual influences on identity construction, enumerate steps in the construction process, and describe characteristics of identity construction.

The concept of organizational identity was originally proposed in the literature to refer to those features of an organization that are central, distinctive, and enduring [2]. Based on their observation of the strong response by the University of Illinois to a minor budget cut, Albert and Whetten theorized that when core features of an organization were challenged, or when an organization was forced to determine "Who we are as an organization", its members will identify characteristics that formed the essence of the organization, distinguished the organization from others, and continued over time. From this definition, organizational identity construction is the processes that organizations identify their central, distinctive, and enduring characteristics. Recently, booming research on organizational identity construction includes the case studies of single organizations responding to identity threats, the studies of similar organizations constructing their identities, and the theoretical treatments of generic organizations going through identity construction that settle on specific models. What is missing is a comprehensive theory on organizational identity construction as a broad-based theoretical process that includes many types of organizations. The research questions, such as how organizational identity is constructed; what influences the way in which organizations construct their identities; what the events in the process of identity construction are; how we describe the process of identity construction and the content of created identities, still need to be explored, particularly by scholars using anthropological analysis as envisioned by [1]. Also importantly, it has been established that identity legitimacy is integral to the health of organizations, and that organizations must take actions to address threats to the legitimacy of their identity. Yet, what is the utility of organizational action in influencing the success or failure of identity construction? Can organizational action save organizational identity legitimacy, or hasten identity disintegration? More importantly, how are success and failure in organizational identity construction determined? By addressing these identity construction questions through an anthropological perspective, we can create a theoretical framework that examines the contextual influences on identity construction, enumerates steps in the organizational identity construction process, and describes characteristics of identity construction.

Identity construction is a useful optic because organizations must make difficult choices about "who they are". If "who they are"-their organizational identity-is derived from their central, distinctive, and enduring characteristics, organizations must elaborate and negotiate the meaning of these characteristics immediately upon their creation. That is, organizations and stakeholders must negotiate which characteristics are central, distinctive, and enduring, and must come to a consensus about the meanings of those characteristics. Just like what [3] observed, organizational identity construction is a sense-exchanging process where "an organizational stakeholder could author an identity claim 
for a certain purpose, constructing and referencing author-specific self-serving classification schemes that may not coincide with other stakeholders' conceptions. Other's stakeholders will respond with their own counterclaims, attempting to redefine and "edit" the claimed identity, leading to an intensive political game involving power struggles consisting of the cyclical enactment, selection, and retention of intra-and interorganizational interactions (Weick, 1979) [3].

Likewise, threatening events that damage organizational identities raise questions about who organizations really are, and cause organizations to actively seek out an answer to who they really are. This void of certainty about who organizations are necessitates identity construction. Into this void, managers and employees input linguistic claims and representative actions that help determine who the organization is, while stakeholders observe, interpret, and make linguistic statements of their own about who they believe an organization is. Organizational identity construction is to create an answer to the question of 'who we are' through negotiations between the organization and its stakeholders on its central, distinctive, and enduring characteristics. In this sense, any statement, efforts, or acts related to organizations and stakeholders' conceptions of 'who we (they) are' are related to identity construction [4]. Answering the question of 'who we are' incorporates identity, variations of image, and organizational reputation. As [5] pointed out, organizational identity should be viewed as a coin with two sides -on one side lays organizational identity and on the other side lays organizational image and reputation. Some scholars prefer to label this metaphorical coin organizational image, while others label this metaphorical coin organizational identity. Each though, is inseparable from the other and both contribute to answering the questions 'who are we'. Organizational identities cannot be constructed without organizational images and reputation, and the inverse is true as well. The concepts are inter-related, rather than distinct, and contribute equally to the identity construction.

It could be postulated that anthropological analysis on organizational identity construction will discuss contextual influences-those elements that affect organizations' decision making throughout the course of identity construction. Contextual elements influence how organizations search for identity characteristics, which characteristics organizations highlight in negotiations, and how organizations negotiate the meaning of their identity with stakeholders. These contextual influences can be external, internal, or boundary influences that shape how organizations create identities. Research should assess the relative importance of contextual elements compared to the perceptions and actions of organizational leaders and members. Currently, most organizational identity research highlighted the perceptions of members and leaders as determining factors for the identity of organizations. The importance of contextual elements calls into questions the singular focus on perceptions of leaders and members as the reason for specific identities. Anthropological research into organizations facing identity threats that trigger identity construction may help shed light onto whether organizations develop identities as a result of perceptions or outside events and conditions.

Anthropological analysis should also cover the process of identity construction, including multiple distinct yet interactive phases such as triggering, searching, negotiating, stabilizing, and maintaining phases. These phases will explain how organizations respond to threatening events that question its identity, choose relevant identity characteristics to address identity questions, negotiate identity claims through sense-exchanging, and enter into a dynamic equilibrium in which identities are accepted, institutionalized, and maintained. It should also describe the characteristics of identity construction, such as the orientation of identity construction, the process of identity construction, and content of the identities that are created as a result of identity construction. One central issue in the process of identity construction is how organizations search an answer to identity questions. During the searching phase of identity construction, organizations identify characteristics they believe are central and distinctive. When searching for an answer to the question raised by triggering events - 'who are we'-organizations search for what they are and what they are not. To determine what they are, organizations look to reservoirs of organizational characteristics. These reservoirs provide organizations the opportunity to repair a damaged identity or find a new identity that challenges the delegitimizing effect of a triggering event. Organizations search for the attributes that best represent their core functions and provide the most persuasive counterargument to identity questions raised by a triggering event. These core functions could be understood as the central identity characteristics. To determine what they are not, organizations look outward to understand how external stakeholders view the organization and what distinguishes their organization from other organizations. This external outlook will ensure organizations finding its distinctive characteristics that will separate them from others.

What is the mechanism of this searching process by which organizations determine what they are and what they are not? How do organizations identify their central and distinctive characteristics? We could postulate that organizations search for their central and distinctive identity characteristics through assimilation and differentiation. That is, organizations appeal to a larger, broader conceptualization of "who they are" as compared to similar organizations, and "who they are" as compared to their past selves, and then work within those conceptions to carve an identity distinct from their previous identity and distinct from other organizations. The reservoirs of organizational characteristics that organizations turn to in the searching phase represent this broader conception of who they are. Organizations assess the usefulness of adopting general identity characteristics of organizations like theirs. They then select some general characteristics that will help them answer specific questions raised by triggering events. Assimilating them with legitimate peer organizations could 
increase the likelihood of being perceived as legitimate. This could be called assimilation mechanism because organizations join their current understanding of who they are with an overarching sense of the organization as derived from accepted characteristics of similar organizations and from their organizational history. Likewise, because the legitimacy of their previous identity has been questioned, organizations must assess the usefulness of promoting specific identity characteristics unique to their organization. After organizations have identified characteristics that they feel represent who they are, they begin a process of differentiation to separate them from who they are not - namely peer organizations and their own previous identity damaged by triggering events. In doing so, organizations identify their distinctive characteristics. Organizations attempt to distinguish themselves from other organizations by tailoring categorical attributes to their particular organizational situation. Similarly, organizations must distinguish themselves from their own previous identities to show that they have addressed initial identity concerns. This differentiation occurs as organizations determine how to apply the characteristics identified in the assimilation stage to their identity problem at hand.

Managerially, creating an anthropological framework for understanding organizational identity construction could help organizational members anticipate how the identity construction process unfolds and allow members to prepare for likely obstacles along the path of identity construction. Searching for and negotiating identities while recognizing the different ways macro trends and stakeholder decisions can influence the success of particular strategies increases the likelihood of successful identity construction. For example, triggering events could have wide ranging implications for organizational managers since it is imperative for them to respond to identity questions raised by triggering events. Though organizational managers receive little or no warning of oncoming triggering phases of identity construction, recognizing a triggering event as internal or external and understanding what dimensions of their organizations' identity have been questioned will give managers an advantage to lead an organization through the searching the reservoirs of organizational characteristics and negotiating strategically the identity characteristics with various stakeholders.

\section{Conclusion}

Anthropological analysis could build upon and extend on the current understanding on organizational identity construction, and further contribute to a comprehensive framework on organizational identity construction. We envisage that the framework incorporates contextual influences which are those elements that affect organizations' decision making throughout the course of identity construction. These contextual influences can be external, internal, or boundary influences that shape how organizations create identities. The process of identity construction could include several distinct yet interactive phases such as triggering, searching, negotiating, stabilizing, and maintaining phases. These phases explain how organizations respond to threatening events that question its identity, choose relevant identity characteristics to address identity questions, negotiate identity claims, and enter into a dynamic equilibrium in which identities are accepted, institutionalized, and maintained, until next round of triggering events happen. The framework should also describe the characteristics of identity construction such as the orientation of identity construction, the process of identity construction, and content of the identities that are created as a result of identity construction.

\section{References}

1. Wolf E (1990) Facing power; old insights, new questions. American Anthropologist 92 (3): 586-596.

2. Albert S, Whetten D A (1985) Organizational identity. In MJ Hatch, M Schultz (Eds), Organizational identity: A reader: 89-118. Oxford, USA.

3. Ran B, Golden TJ (2011) Who are we? The Social Construction of Organizational Identity through Sense-Exchanging. Administration \& Society 43(4): 417-445.

4. Ran B, Duimering PR (2007) Imaging the organization: Language use in organizational identity claims. Journal of Business and Technical Communication 21(2): 155-187.

5. Livengood RS, Reger RK (2010) That's our turf! Identity domains and competitive dynamics. Academy of Management Review 35(1): 48-66.

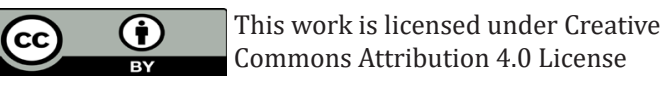

To Submit Your Article Click Here: Submit Article

DOI: 10.32474 /JAAS.2021.06.000227

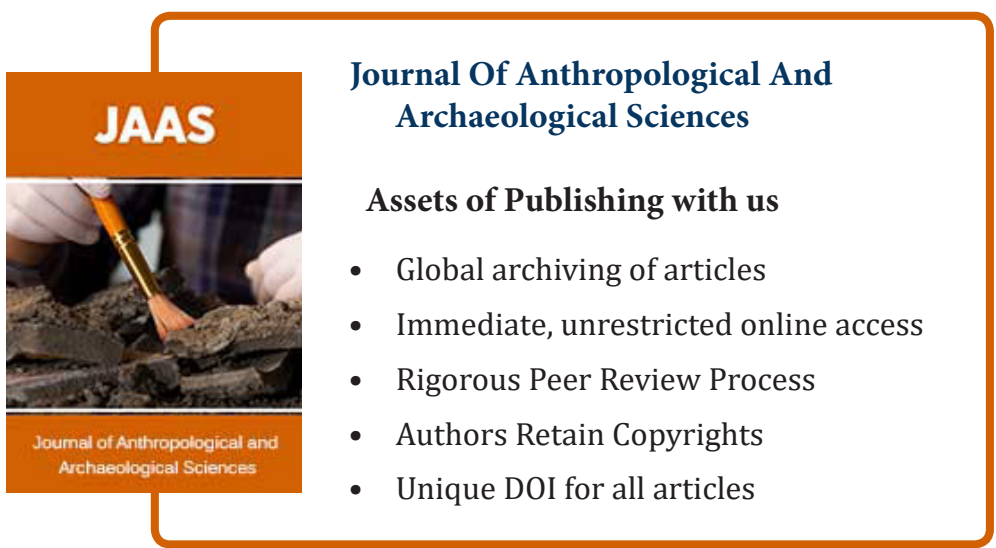

